Arq. Bras. Med. Vet. Zootec., v.60, n.1, p.209-217, 2008

\title{
Nível de proteína bruta para codornas de corte durante o período de crescimento
}

[Crude protein level for meat type quail during the growing period]

\author{
G.S.S. Corrêa $a^{1,3}$, M.A. Silva ${ }^{2,3^{*}}$, A.B. Corrêa ${ }^{1}$, D.O. Fontes ${ }^{2}$, G.G. Santos ${ }^{1}$, H.R. Lima Neto ${ }^{1}$ \\ ${ }^{1}$ Aluno de pós-graduação - EVUFMG - Belo Horizonte, MG \\ ${ }^{2}$ Escola de Veterinária - UFMG \\ Caixa Postal 567 \\ 30123-970 - Belo Horizonte, MG \\ ${ }^{3}$ Bolsista do CNPq
}

\begin{abstract}
RESUMO
Estudou-se a exigência de proteína bruta de codornas de corte na fase de crescimento. Foram utilizadas 288 codornas européias EV2, de ambos os sexos em delineamento experimental inteiramente ao acaso, cujos tratamentos consistiram de dietas com seis níveis de proteína bruta $(23,25,27,29,31$ e $33 \%)$ e quatro repetições de doze codornas por unidade experimental. Estudaram-se o ganho de peso (g), peso corporal ao final de cada período $(\mathrm{g})$, consumo alimentar $(\mathrm{g})$ e conversão alimentar $(\mathrm{g} / \mathrm{g})$ do nascimento ao $21^{\circ}$ e do nascimento ao $42^{\circ}$ dia de idade. No $42^{\circ}$ dia de idade, foram aleatoriamente amostradas e abatidas quatro aves por unidade experimental (dois machos e duas fêmeas), para registro dos pesos e respectivos rendimentos das carcaças, cortes nobres (coxas e peito), vísceras comestíveis (fígado, moela e coração) e gordura abdominal. Do nascimento ao $21^{\circ}$ dia de idade, houve efeito quadrático dos níveis de proteína da dieta sobre peso corporal, ganho de peso e consumo alimentar, com pontos de máximo em $30,64,30,65$ e $29,02 \%$, respectivamente. A conversão alimentar durante este período apresentou resposta linear, ao nível de proteína bruta da dieta. Houve efeito quadrático dos níveis de proteína bruta da dieta sobre o peso no $42^{\circ}$ dia de idade, com máximo desempenho em 29,93\%. Para o ganho de peso houve resposta linear aos níveis de proteína. Houve efeito quadrático no ganho de peso e no consumo alimentar do nascimento ao $42^{\circ}$ dia de idade, com os pontos de máximo estimados em 29,81 e $29,11 \%$, respectivamente. $\mathrm{O}$ peso corporal antes do abate, o de carcaça e o de peito foram influenciados linearmente pelos níveis de proteína bruta da dieta. Houve interação significativa nível protéico versus sexo. As fêmeas apresentaram resposta linear de rendimento de peito em relação aos níveis protéicos da dieta, enquanto o rendimento do peito dos machos não foi influenciado pela proteína da dieta. Peso corporal, rendimento de peito e peso e rendimento de fígado das fêmeas foram maiores que os dos machos. As exigências de proteína bruta estimada para o máximo ganho de peso de machos e fêmeas de codornas de corte, do nascimento ao $21^{\circ}$ e do nascimento ao $42^{\circ}$ dia de idade são $30,65 \%$ e $29,81 \%$, respectivamente. A exigência para pesos de carcaça e peito é de $33,0 \%$ de proteína bruta da dieta.
\end{abstract}

Palavras-chave: codorna, desempenho, proteína bruta, rendimento de carcaça, composição de carcaça

\begin{abstract}
The crude protein requirements for EV2 quail meat type genetic group during the growing period were estimated in a completely randomized experimental design, using 288 quails of both sex, six levels of crude protein $(23,25,27,29,31$ and 33\%) and four replicates of 12 quails per experimental unit. Body weight (g), weight gain (g), feed intake ( $g$ ) and feed:weight gain ratio $(\mathrm{g} / \mathrm{g})$ were recorded in each period (from hatch to 21 days and from hatch to 42 days of age). At 42 days of age, four quails were randomly
\end{abstract}

Recebido em 8 de março de 2007

Aceito em 17 de dezembro de 2007

*Autor para correspondência (corresponding author)

E-mail: martinho@vet.ufmg.br 


\section{Corrêa et al.}

sampled from each experimental unit (two males and two females) and slaughtered to record weights and yields of carcass, main cuts (thigh and breast) edible giblets (liver, gizzard and heart) and abdominal fat. Quadratic effects of crude protein level on body weight, weight gain and feed intake from hatch to 21 days of age, with maximum performances estimated for quails fed 30.64; 30.65 and $29.02 \%$ crude protein diets, respectively. Feed:weight gain ratio during this period showed a linear response in function of protein level of diet. Quadratic effect of protein level on body weight at 42 days of age was observed, with maximum performances estimated for quails fed 29.93 crude protein diets, while weight gain showed a linear response. Quadratic effects of crude protein level on weight gain and feed intake were also observed, with estimated maximum for quails fed 29.81 and $29.11 \%$ crude protein diets, respectively while body weight and carcass and breast weights were linearly affected. Higher performance were observed for quails fed diets with the highest protein level. A significant crude protein level $x$ sex interaction was observed for breast yield, females showing linear response in function of crude protein level, while no effect on male breast yield was observed. Female body weight and breast and liver yields were higher for males crude protein. Crude protein requirements for maximum female and male weight gains are estimated in $30.65 \%$ from hatch to 21 days and $29.81 \%$ from hatch to 42 days of age while crude protein requirement for carcass and breast weights is estimated in $33 \%$.

Keywords: quail, performance, crude protein, carcass yield, carcass composition

\section{INTRODUÇ̃̃̃O}

A proteína da dieta, seguida pelo componente energético, é o segundo nutriente mais caro e seu balanceamento adequado deve melhorar a competitividade e o rendimento econômico das criações de codornas (Silva et al., 2006).

Entretanto, as informações sobre os níveis protéicos exigidos pelas codornas para produção de carne são escassas. Ainda há muitas controvérsias acerca das recomendações para codornas, quanto aos níveis, fases de crescimento e aptidão produtiva das aves (Fridrich et al., 2005). Segundo Corrêa et al., (2007bc) as exigências nutricionais de codornas de corte são diferentes já que essas apresentam maiores pesos e taxas de crescimento que as de postura.

Diferentemente dos carboidratos e dos lipídeos, que podem ser armazenados tanto como glicogênio hepático ou muscular e em reservas de lipídeos corporais, respectivamente, os aminoácidos e/ou proteínas, quando fornecidos em excesso, não são armazenados pelos animais. Dessa forma, o consumo de aminoácidos em excesso é dispendioso, pois o excesso é catabolizado para formar energia, que é suprida por carboidratos e lipídeos a custo mais baixo.

Os resultados observados por Vohra e Roudybush (1971) não indicam diferença no ganho de peso de codornas alimentadas com dietas contendo níveis de proteína bruta que variaram de 20 a 35\%. Enquanto Marks (1978) observou que o ganho de peso de codornas japonesas, alimentadas com dietas contendo $20 \%$ de proteína bruta no período de duas a seis semanas de idade, foi $96 \%$ menor do que codornas alimentadas com $28 \%$ de proteína bruta no mesmo período.

Lesson e Summers (1997) recomendaram para codornas selecionadas para produção de carne dietas com $28 \%$ de proteína até a sexta semana e $18 \%$ até o abate, enquanto Corrêa et al. (2005) estabeleceram $28 \%$ de proteína bruta para a fase inicial (do sétimo ao $21^{\circ}$ dia de idade) de codornas de corte.

Rajini e Narahari (1998) compararam o desempenho de codornas em crescimento, alimentadas com dietas contendo 24, 26 e $28 \%$ de proteína do nascimento à terceira semana e 18,20 e $22 \%$ da quarta à sexta semana de idade e níveis de energia metabolizável de 2400, 2600 e $2800 \mathrm{kcal}$ de energia metabolizável $/ \mathrm{kg}$ e verificaram melhor conversão alimentar do nascimento à terceira semana com dietas contendo $28 \%$ de proteína bruta, independentemente do teor energético. Da quarta à sexta semana, observaram que o nível de $20 \%$ promoveu melhores ganhos de peso e conversão alimentar, independente do nível energético. Os autores ainda observaram que dietas com $28 \%$ de proteína bruta na fase inicial e $22 \%$ na fase final resultaram em maior rendimento de carcaça, maior porcentagem de gordura na carcaça, 
enquanto o maior teor de energia conduziu ao menor teor protéico e maior teor de gordura na carcaça.

No Brasil, existem poucos trabalhos de pesquisa que procuram estabelecer as exigências nutricionais para codornas de corte e, portanto, há necessidade da realização de mais pesquisas cujos resultados podem favorecer a elaboração de programas de alimentação mais corretos.

Assim, esta pesquisa teve como objetivo estudar o efeito de diferentes níveis de proteína bruta da dieta sobre o desempenho e características de carcaça de codornas de corte do grupo genético EV2, durante o período de crescimento.

\section{MATERIAL E MÉTODOS}

O experimento foi realizado no aviário da Escola de Veterinária - UFMG, em Igarapé, MG. Foram adotados para as análises dois períodos de criação: inicial (nascimento ao $21^{\circ}$ dia de idade) e total (nascimento ao $42^{\circ}$ dia de idade).

Foram utilizadas 288 codornas de corte EV2, de ambos os sexos, com um dia de idade, peso médio inicial de $8,0 \mathrm{~g}$, que foram alojadas em baterias de arame galvanizado com dimensões de $0,82 \mathrm{~m}$ de largura $\mathrm{x} 0,41 \mathrm{~m}$ de profundidade $\mathrm{x}$ $0,27 \mathrm{~cm}$ de altura por unidade experimental, equipadas com bebedouro copo e comedouro tipo calha. $\mathrm{O}$ aquecimento das codornas na fase inicial foi realizado com lâmpadas incandescentes de 100 Watts na primeira semana e de 60 watts na segunda semana e o programa de luz adotado, durante a fase experimental, foi de 24 horas.

O delineamento experimental foi inteiramente ao acaso, com seis níveis de proteína bruta $(23,25$, $27,29,31$ e $33 \%$ ), e quatro repetições de 12 codornas por unidade experimental.

As dietas experimentais (Tab. 1) foram formuladas com base na composição dos ingredientes apresentada por Rostagno et al. (2000) e as exigências nutricionais das codornas, de acordo com o NRC (Nutrient..., 1994), exceto para os níveis de proteína bruta $(\mathrm{PB})$.
O desempenho foi avaliado pelo ganho de peso (g), peso ao final de cada período $(\mathrm{g})$, consumo alimentar (g/ave) e conversão alimentar ( $g$ de dieta/g de peso) no período inicial (do nascimento aos 21 dias) e período total (nascimento aos 42 dias).

A avaliação do desempenho e dos rendimentos de carcaça, cortes nobres e vísceras comestíveis foi feita no $42^{\circ}$ dia de idade. Quatro aves (dois machos e duas fêmeas), por unidade experimental, foram amostradas, pesadas e abatidas após jejum de oito horas. Ao modelo estatístico anteriormente estabelecido incluíramse o efeito de sexo e de sua interação com os níveis de proteína bruta da dieta. Após a pesagem da carcaça eviscerada, sem pés e sem cabeça, foram separadas e pesadas as vísceras comestíveis (coração, fígado e moela limpa), a gordura abdominal, em volta da cloaca, moela e proventrículo, foi retirada, e o peito e as pernas (coxas + sobrecoxas) foram pesados.

O rendimento de carcaça, expresso em porcentagem, foi obtido pela relação entre o peso da carcaça eviscerada (sem pés e sem cabeça) e o peso ao abate. Os rendimentos dos cortes (peito, pernas), vísceras comestíveis e gordura abdominal foram calculados com relação ao peso da carcaça eviscerada.

As análises dos dados foram realizadas por meio do programa SAEG (Sistema...2004). As exigências de proteína bruta foram obtidas regredindo-se as variáveis respostas em relação aos níveis de proteína bruta em seus componentes lineares e quadráticos, para escolha do modelo de regressão que melhor descrevesse as observações.

\section{RESULTADOS E DISCUSSÃO}

Do nascimento ao $21^{\circ}$ dia de idade, houve efeito quadrático dos níveis de proteína da dieta sobre peso corporal, ganho de peso e consumo alimentar das codornas (Tab. 2), com pontos de máximo em 30, 64, 30,65 e 29,02\% de $\mathrm{PB}$, respectivamente. 
Tabela 1. Composição percentual e calculada das dietas experimentais

\begin{tabular}{|c|c|c|c|c|c|c|}
\hline \multirow{2}{*}{ Ingredientes $(\%)$} & \multicolumn{6}{|c|}{ Proteína bruta (\%) } \\
\hline & 23 & 25 & 27 & 29 & 31 & 33 \\
\hline Milho & 57,94 & 51,17 & 44,93 & 38,40 & 31,88 & 25,36 \\
\hline Farelo de soja & 36,78 & 42,48 & 47,78 & 53,30 & 58,81 & 64,32 \\
\hline Farinha de carne e osso & 2,60 & 2,60 & 2,60 & 2,60 & 2,60 & 2,60 \\
\hline Óleo de soja & 0,33 & 1,46 & 2,45 & 3,52 & 4,58 & 5,65 \\
\hline Calcário & 0,86 & 0,84 & 0,82 & 0,79 & 0,77 & 0,75 \\
\hline Fosfato bicálcico & 0,16 & 0,13 & 0,11 & 0,08 & 0,05 & 0,02 \\
\hline Suplem. min. e vit. ${ }^{1}$ & 0,50 & 0,50 & 0,50 & 0,50 & 0,50 & 0,50 \\
\hline Sal comum & 0,23 & 0,22 & 0,22 & 0,21 & 0,21 & 0,20 \\
\hline DL- metionina & 0,10 & 0,15 & 0,19 & 0,23 & 0,28 & 0,32 \\
\hline L-treonina & 0,06 & 0,11 & 0,13 & 0,17 & 0,20 & 0,23 \\
\hline Inerte & 0,44 & 0,34 & 0,28 & 0,20 & 0,12 & 0,05 \\
\hline Total & 100,00 & 100,00 & 100,00 & 100,00 & 100,00 & 100,00 \\
\hline \multicolumn{7}{|l|}{ Composição calculada } \\
\hline Proteína bruta (\%) & 23,00 & 25,00 & 27,00 & 29,00 & 31,00 & 33,00 \\
\hline En. metab. (kcal/kg) & 2900 & 2900 & 2900 & 2900 & 2900 & 2900 \\
\hline Cálcio (\%) & 0,80 & 0,80 & 0,80 & 0,80 & 0,80 & 0,80 \\
\hline Fósf. disponível (\%) & 0,30 & 0,30 & 0,30 & 0,30 & 0,30 & 0,30 \\
\hline Fósf. total (\%) & 0,54 & 0,55 & 0,56 & 0,58 & 0,59 & 0,60 \\
\hline Gordura (\%) & 3,12 & 4,10 & 4,93 & 5,84 & 6,74 & 7,65 \\
\hline Lisina disgestível (\%) & 1,10 & 1,23 & 1,35 & 1,47 & 1,60 & 1,73 \\
\hline Lisina total $(\%)$ & 1,23 & 1,37 & 1,50 & 1,64 & 1,77 & 1,91 \\
\hline Met.+Cist. total (\%) & 0,81 & 0,76 & 0,99 & 1,08 & 1,17 & 1,26 \\
\hline Metionina digestível(\%) & 0,42 & 0,35 & 0,55 & 0,62 & 0,69 & 0,75 \\
\hline Metionina total $(\%)$ & 0,55 & 0,48 & 0,69 & 0,76 & 0,83 & 0,90 \\
\hline Sódio (\%) & 0,15 & 0,15 & 0,15 & 0,15 & 0,15 & 0,15 \\
\hline Treonina digestível (\%) & 0,82 & 0,93 & 1,03 & 0,12 & 1,22 & 1,31 \\
\hline Treonina total $(\%)$ & 0,95 & 1,07 & 1,17 & 1,28 & 1,38 & 1,49 \\
\hline Triptofano digestível (\%) & 0,25 & 0,28 & 0,31 & 0,34 & 0,37 & 0,40 \\
\hline Triptofano total (\%) & 0,28 & 0,31 & 0,34 & 0,38 & 0,41 & 0,44 \\
\hline
\end{tabular}

${ }^{1}$ Composição por quilo: vit.A - 2.000.000UI; vit $\mathrm{D}_{3}-375.000 \mathrm{UI}$; vit.E - 3.750mg; vit.k $\mathrm{k}_{3}-500 \mathrm{mg}$; vit. $\mathrm{B}_{1}$ - 250mg; vit. $\mathrm{B}_{2^{-}} 750 \mathrm{mg}$; vit. $\mathrm{B}_{6}-500 \mathrm{mg}$; vit $\mathrm{B}_{12}-3.750 \mathrm{mcg}$; niacina- $6.250 \mathrm{mg}$; ac. pantotênico- $2.500 \mathrm{mg}$; biotina- $10 \mathrm{mg}$; ac. fólico-125mg; colina-75.000mg; selênio-45mg; iodo-175mg; ferro-12.525mg; cobre-2.500mg; manganês-19.500mg; zinco- $13.750 \mathrm{mg}$; avilamicina-15.000mg; narasin-12.250mg; B.H.T.-500mg; vit.C-12.500mg.

A conversão alimentar durante esse período apresentou resposta linear (Tab. 2), de acordo com a equação $\hat{Y}_{i}=3,54-0,051 X_{i}$, portanto, a melhor conversão alimentar ocorreu para codornas alimentadas com dietas contendo maior nível de proteína bruta, ou seja, 33\%. Esses resultados demonstram o quanto as codornas de corte são exigentes em proteína do nascimento ao $21^{\circ}$ dia de idade em decorrência de sua alta taxa de crescimento. Resultados semelhantes foram observados por Almeida (2001), que verificou maior peso de codornas de corte italianas em relação às codornas japonesas desde o primeiro dia de idade (13\%, para machos e fêmeas). Salienta o autor que esta diferença se amplia para 67 e $75 \%$ para fêmeas e machos, respectivamente, ao $49^{\circ}$ dia de idade, portanto com maior exigência em proteína.
Exigências altas de PB, de 285 a 325, para a fase inicial, do nascimento ao $14^{\circ}$ dia de idade, para codornas japonesas foram também relatadas por Shim e Vohra (1984). Contudo, os autores verificaram que o crescimento diferenciado das codornas alimentadas com teores mais altos não foi observado após a terceira semana de idade, em função do crescimento compensatório.

Kirkpinar et al. (1995), ao trabalharem com seis dietas protéicas para codornas japonesas, que variaram de 16 a $30 \%$ de $\mathrm{PB}$, verificaram rápido aumento na taxa de crescimento das aves com o aumento do teor de proteína da dieta. Os resultados indicaram $30 \%$ de $\mathrm{PB}$ como nível adequado de PB das dietas para as codornas atingirem maior peso corporal. 
Tabela 2. Efeito dos níveis de proteína bruta sobre o peso final, ganho de peso, consumo de ração e conversão alimentar das codornas de corte do nascimento ao $21^{\circ}$ dia de idade

\begin{tabular}{|c|c|c|c|c|}
\hline \multirow[b]{2}{*}{$\begin{array}{l}\text { Nível de PB } \\
\quad(\%)\end{array}$} & \multicolumn{4}{|c|}{ Variáveis } \\
\hline & $\begin{array}{l}\text { Peso final } \\
(\mathrm{g})\end{array}$ & $\begin{array}{l}\text { Ganho de peso } \\
\text { (g) }\end{array}$ & Consumo de ração & $\begin{array}{l}\text { Conversão alimentar } \\
(\mathrm{g} / \mathrm{g})\end{array}$ \\
\hline 23 & 97,10 & 89,01 & 215,23 & 2,42 \\
\hline 25 & 111,26 & 103,15 & 232,58 & 2,26 \\
\hline 27 & 141,06 & 133,01 & 269,71 & 2,03 \\
\hline 29 & 143,91 & 135,81 & 286,14 & 2,11 \\
\hline 31 & 148,41 & 140,34 & 294,60 & 2,10 \\
\hline 33 & 141,02 & 132,95 & 237,41 & 1,79 \\
\hline $\mathrm{CV}$ & 2,73 & 2,92 & 2,77 & 3,15 \\
\hline Significância & $*$ & $*$ & $*$ & $*$ \\
\hline & \multicolumn{3}{|c|}{ Equação de regressão } & $\begin{array}{l}\text { Nível de melhor } \\
\text { desempenho }\end{array}$ \\
\hline Peso aos 21 dias & \multicolumn{3}{|c|}{$\hat{Y}_{i}=-723,52+57,00 X_{i}-0,93 X_{i}^{2}\left(\mathrm{R}^{2}=0,95\right)$} & 30,64 \\
\hline Ganho de peso & \multicolumn{3}{|c|}{$\hat{Y}_{i}=-731,74+57,01 X_{i}-0,93 X_{i}^{2}\left(\mathrm{R}^{2}=0,95\right)$} & 30,65 \\
\hline Consumo alimentar & \multicolumn{3}{|c|}{$\hat{Y}_{i}=-1549,77+126,32 X_{i}-2,18 X_{i}^{2}\left(\mathrm{R}^{2}=0,82\right)$} & 29,02 \\
\hline Conversão alimentar & \multicolumn{3}{|c|}{$\hat{Y}_{i}=3,54-0,051 X_{i}\left(\mathrm{R}^{2}=0,79\right)$} & 33,00 \\
\hline
\end{tabular}

*=significativo; ns=não significativo.

Hyánková et al. (1997), ao pesquisarem o efeito dos níveis mais baixos e altos de PB, 19,5 a $26,0 \%$, sobre diferentes linhagens de codornas japonesas de corte, verificaram que para a fase inicial, do nascimento a 14 dias, o máximo desempenho das codornas foi obtido com dietas contendo níveis mais altos de proteína.

Corrêa et al. (2007b) observaram maior ganho de peso do sétimo ao $15^{\circ}$ dia de idade para codornas de corte alimentadas com dietas com $25,7 \%$ de proteína, e maior ganho de peso do $16^{\circ}$ ao $21^{\circ}$ dia de idade, quando alimentadas com $27,9 \%$ de PB. Estes mesmos autores (Corrêa et al., 2007d) em outro experimento, com codornas de corte, observaram melhor desempenho no peso corporal no $21^{\circ}$ dia, ganho de peso do $1^{\circ}$ ao $21^{\circ}$ dia e no consumo alimentar quando estas aves foram alimentadas com dietas contendo $30 \%$ de PB.

Estes resultados, portanto, sustentam a hipótese de que o valor de $24 \%$, estabelecido para proteína bruta pelo NRC (Nutrient..., 1994) para codornas em crescimento, não atende as exigências para máximo ganho de peso das codornas de corte, conforme observado por Corrêa et al. (2006).
Houve efeito quadrático dos teores de PB da dieta sobre o ganho de peso e o consumo alimentar do nascimento ao $42^{\circ}$ dia de idade (Tab. 3), com os pontos de máximo estimados em 29,81 e 29,11\%. Estes resultados são semelhantes aos observados por: Serafin (1982) que, ao trabalhar com dietas com teores de proteína de $24,26,28,30$ e $32 \%$, verificou que codornas Bobwhite tiveram maior peso corporal quando alimentadas com dietas contendo $30 \%$ de $\mathrm{PB}$, no período de 1 a 35 dias de idade; Corrêa et al. (2005) que estimaram nível de $28 \%$ de PB para codornas de corte durante o período de crescimento $\left(7^{\circ}\right.$ ao $42^{\circ}$ dia de idade) e Corrêa et al. (2007d) que estimaram a exigência em 29,4\% de proteína bruta para codornas de corte do $1^{\circ}$ ao $42^{\circ}$ dia de idade.

Portanto, os resultados experimentais sugerem a necessidade de formulação de dietas para codornas de corte com altos teores de proteína bruta, por estarem diretamente relacionados à velocidade de crescimento e à capacidade de deposição de massa muscular. Corrêa et al. (2007a) observaram diminuição no nível nutricional exigido para máximo desempenho das codornas de corte com o avanço da idade, o que, segundo os autores, pode estar relacionado ao menor ganho de peso da fase final de criação comparado com o da fase inicial. 


\section{Corrêa et al.}

Tabela 3. Efeito dos níveis de proteína bruta sobre o peso final, ganho de peso, consumo de ração e conversão alimentar das codornas de corte do nascimento ao $42^{\circ}$ dia de idade

\begin{tabular}{cccc}
\hline $\begin{array}{l}\text { Nível de PB } \\
(\%)\end{array}$ & $\begin{array}{c}\text { Ganho de peso } \\
(\mathrm{g})\end{array}$ & $\begin{array}{c}\text { Consumo de ração } \\
(\mathrm{g})\end{array}$ & $\begin{array}{c}\text { Conversão alimentar } \\
(\mathrm{g} / \mathrm{g})\end{array}$ \\
\cline { 2 - 4 } & 234,44 & 760,35 & 3,25 \\
23 & 244,06 & 805,79 & 3,30 \\
25 & 276,57 & 877,93 & 3,18 \\
27 & 266,81 & 859,91 & 3,22 \\
29 & 270,69 & 886,74 & 3,28 \\
31 & 265,23 & 820,27 & 3,09 \\
\hline 33 & 3,39 & 2,47 & 3,43 \\
\hline CV & $*$ & $*$ & ns \\
\hline Significância & \multicolumn{2}{c}{ Equação de regressão } & desempenho \\
\hline \multicolumn{2}{c}{ Ganho de peso } & $\hat{Y}_{i}=-484,73+50,67 X_{i}-0,85 X_{i}^{2}\left(\mathrm{R}^{2}=0,84\right)$ & 29,81 \\
\hline Consumo alimentar & $\hat{Y}_{i}=-1928,77+192,69 X_{i}-3,31 X_{i}^{2}\left(\mathrm{R}^{2}=0,89\right)$ & 29,11 \\
\hline *=significativo; ns=não significativo
\end{tabular}

Kirkpinar e Oguz (1995), ao trabalharem com dietas com 16, 20, 22, 25, 28 e $30 \%$ de PB, verificaram maiores pesos de codornas alimentadas com dietas contendo $30 \%$ de $\mathrm{PB}$, do nascimento ao $35^{\circ}$ dia de idade. Murakami et al. (1993) e Hyánková et al. (1997) não encontraram efeito significativo dos níveis de proteína sobre o consumo de codornas japonesas de ambos os sexos, do nascimento ao $42^{\circ}$ dia de idade e do nascimento ao $35^{\circ}$ dia de idade, respectivamente, em dietas com níveis protéicos que variaram de 20 a 26 e 19,5 a $26,0 \%$ de $\mathrm{PB}$, respectivamente.

Oliveira et al. (2002) também, ao trabalharem com codornas de corte, observaram interação significativa para o nível protéico $\mathrm{x}$ sexo para peso médio final e para ganho de peso do nascimento ao $49^{\circ}$ dia de idade, não observaram influência do nível protéico sobre o desempenho dos machos, porém as fêmeas apresentaram maior ganho de peso quando alimentadas com dietas à base de $24 \%$ de $\mathrm{PB}$.

O peso corporal antes do abate, de carcaça e de peito foram influenciados pelos níveis de proteína bruta da dieta (Tab. 4), de acordo com as equações $\hat{Y}_{i}=189,15+2,41 X_{i} ; \hat{Y}_{i}=130,05$ $+1,68 X_{i}$ e $\hat{Y}_{i}=27,62+1,46 X_{i}$, de forma que as codornas tiveram melhores desempenhos nos níveis mais altos de PB.

Houve interação significativa entre o nível protéico e sexo (Tab. 4 e 5), as fêmeas apresentaram respostas lineares do rendimento de peito em função dos níveis protéicos da dieta, segundo a equação $\hat{Y}_{i}=20,67+0,64 X_{i}$ e o rendimento do peito dos machos não sofreu influência dos níveis protéicos da dieta.

Corrêa et al. (2004) não observaram diferenças nos pesos e rendimento de peito de codornas de corte alimentadas com diferentes níveis protéicos. Costa et al. (2001), ao trabalharem com diferentes níveis protéicos para frangos de corte, não observaram diferença para rendimento de carcaça e rendimento de filé de peito; no entanto, os autores observaram que, ao se elevar a ingestão protéica pelo aumento da proteína da dieta, houve maior rendimento de peito com osso.

Kirkpinar e Oguz (1995) observaram que o peso de carcaça mostrou resposta quadrática aos conteúdos crescentes de proteína da dieta. Rajini e Narahari (1998) verificaram que os níveis de $28 \%$ de PB na fase inicial e de $22 \%$ na fase final resultaram em maior rendimento de carcaça e menor percentagem de gordura na carcaça. 
Tabela 4. Peso médio das codornas (g), carcaça eviscerada (g) e dos respectivos cortes de carcaça (g) e vísceras comestíveis $(\mathrm{g})$, em função dos níveis de proteína bruta $(\mathrm{PB})$ das dietas

\begin{tabular}{|c|c|c|c|c|c|c|c|c|}
\hline \multirow{2}{*}{ Variáveis } & \multirow{2}{*}{ Sexo } & \multicolumn{6}{|c|}{ Níveis de proteína bruta (\%) } & \multirow{2}{*}{ Média } \\
\hline & & 23 & 25 & 27 & 29 & 31 & 33 & \\
\hline \multirow{2}{*}{ Peso corporal $(\mathrm{g})$} & $\mathrm{M}$ & 223,50 & 233,50 & 258,50 & 247,25 & 259,75 & 236,50 & $243,17 B$ \\
\hline & $\mathrm{F}$ & 268,75 & 234,25 & 278,00 & 276,75 & 280,00 & 282,50 & $270,04 \mathrm{~A}$ \\
\hline \multirow{2}{*}{$\begin{array}{l}\text { Peso de carcaça } \\
(\mathrm{g})\end{array}$} & $\mathrm{M}$ & 160,00 & 165,50 & 188,75 & 178,50 & 177,25 & 179,00 & $174,83 \mathrm{~A}$ \\
\hline & $\mathrm{F}$ & 182,00 & 158,00 & 182,75 & 177,75 & 191,25 & 186,25 & $179,67 \mathrm{~A}$ \\
\hline \multirow{2}{*}{ Peso de coxa $(g)$} & $\mathrm{M}$ & 43,25 & 42,00 & 44,00 & 45,00 & 42,25 & 40,00 & $42,75 \mathrm{~A}$ \\
\hline & $\mathrm{F}$ & 48,25 & 42,00 & 42,25 & 43,25 & 45,50 & 46,25 & $44,58 \mathrm{~A}$ \\
\hline \multirow{2}{*}{ Peso de peito (g) } & $\mathrm{M}$ & 59,00 & 61,75 & 71,25 & 69,75 & 74,75 & 66,75 & $67,21 \mathrm{~A}$ \\
\hline & $\mathrm{F}$ & 64,25 & 58,50 & 69,75 & 69,50 & 77,00 & 78,75 & $69,63 \mathrm{~A}$ \\
\hline \multirow{2}{*}{ Peso de fígado $(\mathrm{g})$} & $\mathrm{M}$ & 3,98 & 4,88 & 4,78 & 4,13 & 4,78 & 4,33 & $4,48 \mathrm{~B}$ \\
\hline & $\mathrm{F}$ & 4,73 & 4,60 & 5,70 & 5,98 & 5,73 & 5,83 & $5,43 \mathrm{~A}$ \\
\hline \multirow{2}{*}{ Peso de moela (g) } & $\mathrm{M}$ & 3,73 & 4,63 & 3,83 & 3,70 & 3,90 & 3,65 & $3,90 \mathrm{~A}$ \\
\hline & $\mathrm{F}$ & 4,55 & 4,15 & 4,08 & 3,63 & 4,53 & 4,15 & $4,18 \mathrm{~A}$ \\
\hline \multirow{2}{*}{$\begin{array}{l}\text { Peso de coração } \\
(\mathrm{g})\end{array}$} & $\mathrm{M}$ & 1,93 & 2,43 & 2,05 & 2,18 & 2,00 & 2,20 & $2,13 \mathrm{~A}$ \\
\hline & $\mathrm{F}$ & 2,30 & 2,13 & 2,40 & 2,25 & 2,28 & 2,60 & $2,33 \mathrm{~A}$ \\
\hline \multirow{3}{*}{ Peso de GA (g) } & $\mathrm{M}$ & 2,15 & 2,25 & 3,08 & 3,63 & 3,38 & 2,30 & $2,80 \mathrm{~A}$ \\
\hline & $\mathrm{F}$ & 2,93 & 2,65 & 4,30 & 2,83 & 3,08 & 3,58 & $3,23 \mathrm{~A}$ \\
\hline & \multicolumn{5}{|c|}{$\begin{array}{c}\text { Equações de regressão significativas para } \\
\text { níveis de PB }\end{array}$} & \multicolumn{3}{|c|}{ Nível de melhor desempenho } \\
\hline Peso corporal & \multicolumn{5}{|c|}{$\hat{Y}_{i}=189,15+2,41 X_{i}\left(\mathrm{R}^{2}=0,42\right)$} & \multicolumn{3}{|c|}{33,00} \\
\hline Peso de carcaça & \multicolumn{4}{|c|}{$\hat{Y}_{i}=130,05+1,68 X_{i}\left(\mathrm{R}^{2}=0,46\right)$} & & \multicolumn{2}{|r|}{33,00} & \\
\hline Peso de peito & \multicolumn{4}{|c|}{$\hat{Y}_{i}=27,62+1,46 X_{i}\left(\mathrm{R}^{2}=0,76\right)$} & & \multicolumn{2}{|r|}{33,00} & \\
\hline
\end{tabular}

Médias seguidas de letras distintas entre os sexos, dentro de cada variável diferem pelo teste Fisher $(\mathrm{p}<0,05)$.

Tabela 5. Rendimentos das carcaças e dos respectivos cortes de carcaça e vísceras comestíveis (\%), em função dos níveis de proteína bruta $(\mathrm{PB})$ das dietas

\begin{tabular}{|c|c|c|c|c|c|c|c|c|}
\hline \multirow{2}{*}{ Variáveis } & \multirow{2}{*}{ Sexo } & \multicolumn{6}{|c|}{ Níveis de proteína bruta (\%) } & \multirow{2}{*}{ Média } \\
\hline & & 23 & 25 & 27 & 29 & 31 & 33 & \\
\hline \multirow{2}{*}{$\begin{array}{l}\text { Rendimento de } \\
\text { carcaça }(\%)\end{array}$} & $\mathrm{M}$ & 71,59 & 70,92 & 73,00 & 72,10 & 68,15 & 75,91 & $71,95 \mathrm{~A}$ \\
\hline & $\mathrm{F}$ & 67,80 & 67,56 & 66,00 & 64,24 & 68,46 & 65,80 & $66,64 \mathrm{~A}$ \\
\hline \multirow{2}{*}{$\begin{array}{l}\text { Rendimento de } \\
\text { coxa }(\%)\end{array}$} & $\mathrm{M}$ & 26,97 & 25,32 & 23,38 & 25,33 & 24,10 & 22,42 & $24,59 \mathrm{~A}$ \\
\hline & $\mathrm{F}$ & 26,65 & 26,57 & 23,19 & 24,40 & 23,86 & 24,92 & $24,93 \mathrm{~A}$ \\
\hline \multirow{2}{*}{$\begin{array}{l}\text { Rendimento de } \\
\text { peito }(\%)\end{array}$} & $\mathrm{M}$ & 36,86 & 37,37 & 37,73 & 39,11 & 41,92 & 37,20 & $38,37 \mathrm{~B}$ \\
\hline & $\mathrm{F}$ & 35,34 & 37,04 & 38,19 & 39,05 & 40,27 & 42,25 & $38,69 \mathrm{~A}$ \\
\hline \multirow{2}{*}{$\begin{array}{l}\text { Rendimento de } \\
\text { fígado }(\%)\end{array}$} & $\mathrm{M}$ & 2,49 & 2,94 & 2,50 & 2,30 & 2,67 & 2,39 & $2,55 \mathrm{~B}$ \\
\hline & $\mathrm{F}$ & 2,60 & 2,91 & 3,12 & 3,37 & 3,00 & 3,15 & $3,03 \mathrm{~A}$ \\
\hline \multirow{2}{*}{$\begin{array}{l}\text { Rendimento de } \\
\text { moela }(\%)\end{array}$} & $\mathrm{M}$ & 2,32 & 2,79 & 2,02 & 2,10 & 2,18 & 2,03 & $2,24 \mathrm{~A}$ \\
\hline & $\mathrm{F}$ & 2,51 & 2,63 & 2,24 & 2,04 & 2,36 & 2,24 & $2,34 \mathrm{~A}$ \\
\hline \multirow{2}{*}{$\begin{array}{l}\text { Rendimento de coração } \\
(\%)\end{array}$} & $\mathrm{M}$ & 1,20 & 1,46 & 1,09 & 1,21 & 1,13 & 1,23 & $1,22 \mathrm{~A}$ \\
\hline & $\mathrm{F}$ & 1,27 & 1,34 & 1,31 & 1,26 & 1,18 & 1,37 & $1,29 \mathrm{~A}$ \\
\hline \multirow{3}{*}{$\begin{array}{c}\text { Rendimento de } \\
\text { GA }(\%)\end{array}$} & $\mathrm{M}$ & 1,35 & 1,37 & 1,61 & 2,10 & 1,89 & 1,28 & $1,60 \mathrm{~A}$ \\
\hline & $\mathrm{F}$ & 1,61 & 1,68 & 2,35 & 1,59 & 1,60 & 1,90 & $1,79 \mathrm{~A}$ \\
\hline & \multicolumn{6}{|c|}{ Equações de regressão significativas para níveis de PB } & \multicolumn{2}{|c|}{$\begin{array}{l}\text { Nível de melhor } \\
\text { desempenho }\end{array}$} \\
\hline $\begin{array}{l}\text { Rendimento de peito } \\
\text { (fêmeas) }\end{array}$ & \multicolumn{6}{|c|}{$\hat{Y}_{i}=20,67+0,64 X_{i}\left(\mathrm{R}^{2}=0,76\right)$} & \multicolumn{2}{|c|}{33,00} \\
\hline
\end{tabular}

Médias seguidas de letras distintas entre os sexos, dentro de cada variável diferem pelo teste Fisher $(\mathrm{p}<0,05)$. 
O peso corporal, o rendimento de peito e o peso e rendimento de fígado das fêmeas foram maiores que os dos machos, o que sugere que, no $42^{\circ}$ dia de idade, codornas apresentam comportamento diferente de frangos de corte, no qual os machos apresentam maiores taxas de crescimento. Isso pode ser explicado pelo acentuado dimorfismo sexual apresentado pelas codornas e pela maior precocidade das fêmeas em relação aos machos. Os maiores peso e rendimento de fígado das fêmeas são justificáveis pela precocidade da produção das codornas que iniciaram a postura e se encontram em plena fase de reprodução, em que há intensa síntese de lipídeos no fígado nesta idade, para garantir o desenvolvimento dos folículos.

Apesar de as fêmeas apresentarem melhor desempenho para algumas características, os resultados indicam que não há diferença entre as exigências de $\mathrm{PB}$ entre os sexos, assim, não há necessidade do estabelecimento de dietas com níveis protéicos diferenciados para codornas de ambos os sexos, durante o período de crescimento, do nascimento aos 42 dias de idade.

\section{CONCLUSÕES}

A exigência de proteína bruta para o máximo ganho de peso de machos e fêmeas de codornas de corte EV2 em crescimento, do nascimento ao $21^{\circ}$ dia de idade, é estimada em $30,65 \%$ e do nascimento ao $42^{\circ}$ dia em $29,81 \%$ da dieta, correspondendo aos consumos de $4,090 \mathrm{~g}$ e $6,173 \mathrm{~g}$ de proteína/dia/codorna, respectivamente. Maiores pesos de carcaça e peito são observados para codornas alimentadas com dietas contendo $33 \%$ de proteína bruta.

\section{AGRADECIMENTOS}

Ao CNPq, pelo financiamento do projeto.

\section{REFERÊNCIAS BIBLIOGRÁFICAS}

ALMEIDA, M.I.M. Efeito da linhagem e de nivel protéico sobre o desempenho $e$ características de carcaça de codornas (Coturnix sp.) criadas para corte. 2001. 135f. Tese (Doutorado) - Universidade Estadual Paulista, Botucatu.

CORRÊA, G.S.S.; SILVA, M.A.; CORRÊA, A.B. et al. Desempenho de codornas de corte
EV1 alimentadas com diferentes níveis de lisina na dieta. Arq. Bras. Med. Vet. Zootec., v.59, p.1545-1553, 2007a.

CORRÊA, G.S.S.; SILVA, M.A.; FONTES, D.O. et al. Efeito de diferentes níveis de proteína e energia sobre o rendimento de carcaça de codornas européias. Arq. Bras. Med. Vet. Zootec., v.57, p. 266-271, 2005.

CORRÊA, G.S.S.; SILVA, M.A.; CORRÊA, A.B. et al. Exigência de metionina + cistina para codornas de corte em crescimento. Arq. Bras. Med. Vet. Zootec., v.58, p.414-420, 2006.

CORRÊA, G.S.S.; SILVA, M.A.; CORRÊA, A.B. et al. Exigência de proteína bruta e energia metabolizável em codornas de corte durante a fase de crescimento. Arq. Bras. Med. Vet. Zootec., v.59, p.488-494, $2007 \mathrm{~b}$.

CORRÊA, G.S.S.; SILVA, M.A.; CORRÊA, A.B. et al. Exigência de proteína bruta e energia metabolizável para codornas de corte EV1. Arq. Bras. Med. Vet. Zootec., v.59, p.797-804, 2007c.

CORRÊA, G.S.S.; SILVA, M.A.; CORRÊA, A.B. et al. Exigência de proteína bruta para codornas de corte EV1 em crescimento. Arq. Bras. Med. Vet. Zootec., v.59, p.1278-1286, 2007d.

CORRÊA, G.S.S.; SILVA, M.A.; CORRÊA, A.B. et al. Rendimento de carcaça de codornas de corte alimentadas com dietas com diferentes níveis de proteína bruta e energia metabolizável. In: REUNIÃO ANUAL DA SOCIEDADE BRASILEIRA DE ZOOTECNIA, 41., 2004, Campo Grande. Anais... Campo Grande: SBZ, 2004.

COSTA, E.G.P.; ROSTAGNO, H.S.; ALBINO, L.F.T. et al. Níveis dietéticos de lisina para frangos de corte de 1 a 21 dias e 22 a 40 dias de idade. Rev. Bras. Zootec., v.30, p.1490-1497, 2001.

FRIDRICH, A.B.; VALENTE, B.D.; SILVA, A.F. et al. Exigência de proteína bruta para codornas européias no período de crescimento. Arq. Bras. Med. Vet. Zootec., v.57, p.261-265, 2005.

HYÁNKOVÁ, L.; DEDKOVÁ, L.; KNIZETVÁ, $\mathrm{H}$. et al. Responses in growth, food intake and food conversion efficiency to different dietary protein concentrations in meat-type lines of 
Japanese quail. Br. Poult. Sci., v.38, p.564-570, 1997.

KIRKIPINAR, F.; OGUZ, I. Influence of various dietary protein levels on carcass composition in the male Japanese quail (Coturnix coturnix japonica). Br. Poult. Sci., v.36, p.605-610, 1995.

LESSON, S.; SUMMERS, J. D. (Eds). Commercial poultry nutrition. 2. ed., Guelph, Ontario, Can.: University Books. 1997. 350p.

MARKS, H.L. Compensatory growth in Japanese quail following protein restriction. Poult. Sci., v.57, p.1473-1477, 1978.

MURAKAMI, A.E.; MORAES, V.M.B.; ARIKI, J. et al. Níveis de proteína e energia em rações para codornas japonesas (Coturnix coturnix japonica) em crescimento. Rev. Bras. Zootec. v.22, p.534-540, 1993.

NUTRIENT requirements of poultry. 9. ed. Washington: National Academy of Sciences, 1994. p.44-45.

OLIVEIRA, E.G.; ALMEIDA, M.I.M.; MENDES, A.A. et al. Desempenho produtivo de codornas de ambos os sexos para corte alimentadas com dietas com quatro níveis protéicos. Arch. Vet. Sci., v.7, p.75-80, 2002.

RAJINI, R.A.; NARAHARI, D. Dietary energy and protein requirements of growing japanese quails in the tropics. India. J. Anim. Sci., v.68, p.1082-1086, 1998.

ROSTAGNO, H.S.; ALBINO, L.F.T.; DONZELE, J.L. et al. Composição de Alimentos $e$ exigências nutricionais de aves e suínos, (Tabelas brasileiras para aves e suínos). Viçosa, MG: UFV, 2000. 141p.

SERAFIN, J.A. Influence of protein level and supplemental methionine in practical rations for young endangered masked Bobwhite quail. Poult. Sci., v.61, p.988-990, 1982.

SHIM, K.F.; VOHRA, P. A review of the nutrition of Japanese quail. World's Poult. Sci. J., v.40, p.261-274, 1984.

SILVA, E.L.; SILVA, J.H.V.; JORDÃO FILHO, J. et al. Redução dos níveis de proteína e suplementação aminoacídica em rações para codornas européias (Coturnix coturnix coturnix). Rev. Bras. Zootec., v.35, p.822-829, 2006.

SISTEMA de análises estatísticas - SAEG. Versão 9.0. Viçosa, MG:UFV, 2004.

VOHRA, P.; ROUDYBUSH, T. The effect of various levels of dietary protein on growth and egg production of Coturnix coturnix japonica. Poult. Sci., v.50, p.1081-1084, 1971. 